\title{
A Case Report: Double Isolation of NDM-1 Producing Enterobacteriaceae in A Military Hospital in Spain
}

\section{Maria Simón Sacristán | Ana Collazos Blanco* | Maria Isabel Zamora Cintas | Francisco Javier Membrillo | Germán Ramirez | María Mateo Maestre}

*Correspondence: Ana Collazos Blanco

Address: Hospital Central de Defensa Gómez Ulla, Madrid, Spain

e-mail $\bowtie$ : acollazosblanco@gmail.com

Received: 16 March 2021; Accepted: 24 March 2021

Copyright: (C) 2021 Sacristán MS. This is an open-access article distributed under the terms of the Creative Commons Attribution License, which permits unrestricted use, distribution, and reproduction in any medium, provided that the original work is properly cited.

\section{ABSTRACT}

New Delhi metallo- $\beta$-lactamase (NDM) is an uncommon type of carbapenemase in our country. Despite this, in recent years the number of isolates of this type of carbapenemase has increased in our country, mainly due to travelers coming from Middle Eastern countries. We report a case of an Iraqi man wounded by an explosive device who arrived at our hospital and who had isolates Staphylococcus aureus which were resistant to ceftobiprole and ceftaroline and NDM-1 producing Klebsiella pneumoniae and Escherichia coli. It must be paid special attention to nationals of countries with a high prevalence of mechanism of resistances, highlighting the importance of an early detection to prevent its spread in our country.

Keywords: Carbapenemase, Klebsiella Pneumoniae, Escherichia Coli

\section{Introduction}

Resistance to antimicrobial agents of pathogenic bacteria has become a major problem in routine medical practices. Carbapenem resistance has long been increasing during the last years. The production of carbapenem-hydrolysing $\beta$-lactamases (carbapenemases), where NDM, KPC, OXA-48, IMP-1 and VIM are the most common mechanisms (Nordmann et al., 2011; Bonomo et al., 2018). Although it is not the most frequent carbapenemase in our environment, NDM type has becoming a serious problem in nosocomial infections in the last years in some countries around the world (Khan et al., 2017). This resistance pattern compromises the efficacy of almost all lactams (except aztreonam), including the last resort carbapenems. Therapeutical options may remain limited mostly to colistin, tigecycline, and fosfomycin.

\section{Presentation of Case}

We present a case of a 49 years old male patient, natural from Iraq, wounded by improvised explosive device (IED) explosion. The IED caused shrapnel wounds predominantly in the right facial region, right skull and upper right member. 
After a first surgery and several weeks of hospitalization, first in Hasaka, (Syria) and then in Dahuk (Iraq) and several cycles of treatments with wound debridement to the bone plane and antimicrobial therapy with vancomycin and meropenen due to the isolation of a Staphylococcus aureus, the patient had a bad evolution. One month later the patient was transferred to our hospital in Madrid (Spain), a cranial CT was performed and showed a right frontal brain abscess which extended from coronal suture to upper cranial base, with bone fragments and intracranial shrapnel. The patient was reintervened and different samples were taken. In bone biopsy of intracranial bone fragments, two different microorganisms were isolated: methicillin-resistant Staphylococcus aureus (MRSA), which showed resistance to ceftobiprole and ceftaroline, and a $\beta$-lactamase-producing $E$. coli, showing a resistance profile described in table 1 . The minimum inhibitory concentration (MIC) was determined by broth microdilution methods (MicroSscan WalkAway, Beackman Coulter) and interpreted according to EUCAST breakpoints (www.eucast.org). After cultures, the patient was treated with linezolid (600mg every 12 hours), fosfomycin (8mg every 8 hours) and tigecycline (100mg every 12 hours).

Ten days later to admission, we also isolated a $\beta$-lactamase-producing $K$. pneumoniae from a sputum screening swab, with similar resistance pattern as E.coli (Table 1). To improve the knowledge of the resistance pattern, a rapid immunochromatographic diagnostic test (RESIST-5 O.K.N.V. Coris BioConcept) was performed in both isolates, obtaining a positive result for NDM metallo- $\beta$-lactamase type. These results were confirmed by Seegene Allplex enteroDR, a novel multiplex real time PCR assay (polymerase chain reaction), which is able to detect eight antibiotic resistant genes: $b l a_{\text {OXA-48, }} b l a_{\mathrm{KPC}}$, bla $_{\mathrm{VIM}}$, bla $_{\mathrm{IMP}}, b l a_{\mathrm{NDM}} b l a_{\mathrm{CTX}-\mathrm{M}}, \mathrm{vanA}$ and vanB. Both of our strains were positive for an extended-spectrum $\beta$ lactamase type CTX-M as well.

The presence of bla $_{\mathrm{NDM}}$ gen type 1 was confirmed in both strains by Multilocus Sequence Typing (MLST) and pulsed-field gel electrophoresis by the National Center for Microbiology "Carlos III" in Madrid (Spain). This find appears to be a possible interspecies plasmid transfer.

\section{Discussion}

This type of carbapenemase is rarely isolated in Spain (Mataseje et al., 2016). The majority of the patients from North America, Europe and Australia infected with NDM producing bacteria were travellers previously hospitalized in middle eastern countries. The first case reported in an industrialized country was in Sweden in 2009 (Yong et al., 2009) and after this, there are sporadic reports from military hospitals Pakistan (Day et al., 2013) and Israel (Lerner et al., 2016), Syrian refugees (Lerner et al., 2016) or travelers returning from India (Oteo et al., 2012; Gil-Romero et al., 2013) and other European countries, as well as USA (Wilson and Chen, 2012), Canada (Mataseje et al., 2016) or Australia (Sidjabat et al., 2011) and even cases of nosocomial dissemination (Poirel et al., 2014). In this report we described 
two different enterobacteriaceae isolated in the same patient with the same resistance pattern suggests a horizontal spread.

Table 1: Sensitivity of Klebsiella pneumoniae, Staphylococcus aureus and Escherichia coli

\begin{tabular}{|c|c|c|c|}
\hline & K. pneumoniae & S. aureus & E. coli \\
\hline Ampiciline & $\mathrm{R}$ & $\mathrm{R}$ & $\mathrm{R}$ \\
\hline Amoxicilin/Clavulanate & $\mathrm{R}$ & $\mathrm{R}$ & $\mathrm{R}$ \\
\hline Cefepime & $\mathrm{R}$ & & $\mathrm{R}$ \\
\hline Cefotaxime & $\mathrm{R}$ & & $\mathrm{R}$ \\
\hline Ceftazidime & $\mathrm{R}$ & & $\mathrm{R}$ \\
\hline Cefuroxime & $\mathrm{R}$ & & $\mathrm{R}$ \\
\hline Ciprofloxacin & $\mathrm{R}$ & $\mathrm{R}$ & $\mathrm{R}$ \\
\hline Ertapenem & $\mathrm{R}$ & & $\mathrm{R}$ \\
\hline Meropenem & $\mathrm{R}$ & & $\mathrm{R}$ \\
\hline Piperaciline/Tazobactam & $\mathrm{R}$ & & $\mathrm{R}$ \\
\hline Tigeciciline & S & S & S \\
\hline Tobramycin & $\mathrm{R}$ & $\mathrm{R}$ & $\mathrm{R}$ \\
\hline Amikacin & $\mathrm{R}$ & $\mathrm{R}$ & $\mathrm{R}$ \\
\hline Ceftolozane/Tazobactam & $\mathrm{R}$ & & $\mathrm{R}$ \\
\hline Ceftazidime/Avibactam & $\mathrm{R}$ & & $\mathrm{R}$ \\
\hline Colistin & S & & S \\
\hline Vancomycin & & S & \\
\hline Erythromycin & & $\mathrm{R}$ & \\
\hline Clindamycin & & $\mathrm{R}$ & \\
\hline Linezolid & & S & \\
\hline Daptomycin & & $\mathrm{R}$ & \\
\hline
\end{tabular}

\section{Conclusion}

Special attention should be given to patients repatriated from conflict zones, mainly those with accumulating risk factors. The use of rapid molecular methods with multiple targets is essential for an early diagnosis, especially in isolates with resistance patterns that are not so common in low-prevalence countries. Clinicians and microbiologists must focus in detecting these organisms and promoting control measures to prevent nosocomial spread of antimicrobial multirresistance. 


\section{References}

Bonomo RA, Burd EM, Conly J, Limbago BM, Poirel L, Segre JA, et al. Carbapenemase-Producing Organisms: A Global Scourge. Clin Infect Dis 2018; 66: 1290-1297.

Day KM, Ali S, Mirza IA, Sidjabat HE, Silvey A, Lanyon CV, Cummings SP, Abbasi SA, Raza MW, Paterson DL, Perry JD. Prevalence and molecular characterization of Enterobacteriaceae producing NDM-1 carbapenemase at a military hospital in Pakistan and evaluation of two chromogenic media. Diagn Microbiol Infect Dis 2013; 75: 187-191.

Gil-Romero Y, Sanz-Rodriguez N, Almagro-Molto M, Gomez-Garces JL. New description of a NDM-1 carbapenemase producing Klebsiella pneumoniae carrier in Spain. Enferm Infecc Microbiol Clin 2013; 31: 418-419.

Khan AU, Maryam L, Zarrilli R. Structure, Genetics and Worldwide Spread of New Delhi Metallo-beta-lactamase (NDM): a threat to public health. BMC Microbiol 2017; 17: 101.

Lerner A, Solter E, Rachi E, Adler A, Rechnitzer H, Miron D, Krupnick L, Sela S, Aga E, Ziv Y, Peretz A. Detection and characterization of carbapenemase-producing Enterobacteriaceae in wounded Syrian patients admitted to hospitals in northern Israel. Eur J Clin Microbiol Infect Dis 2016; 35: 149-154.

Lerner A, Solter E, Rachi E, Adler A, Rechnitzer H, Miron D, Krupnick L, Sela S, Aga E, Ziv Y, Peretz A. Detection and characterization of carbapenemase-producing Enterobacteriaceae in wounded Syrian patients admitted to hospitals in northern Israel. Eur J Clin Microbiol Infect Dis 2016; 35: 149-154.

Mataseje LF, Abdesselam K, Vachon J, Mitchel R, Bryce E, Roscoe D, Boyd DA, Embree J, Katz K, Kibsey P, Simor AE. Results from the Canadian Nosocomial Infection Surveillance Program on Carbapenemase-Producing Enterobacteriaceae, 2010 to 2014. Antimicrob Agents Chemother 2016; 60: 6787-6794.

Mataseje LF, Abdesselam K, Vachon J, Mitchel R, Bryce E, Roscoe D, Boyd DA, Embree J, Katz K, Kibsey P, Simor AE. Results from the Canadian Nosocomial Infection Surveillance Program on Carbapenemase-Producing Enterobacteriaceae, 2010 to 2014. Antimicrob Agents Chemother 2016; 60: 6787-6794.

Nordmann P, Naas T, Poirel L. Global spread of Carbapenemase-producing Enterobacteriaceae. Emerg Infect Dis 2011; 17: 1791-1798.

Oteo J, Domingo-Garcia D, Fernandez-Romero S, Saez D, Guiu A, Cuevas O, Lopez-Brea M, Campos J. Abdominal abscess due to NDM-1-producing Klebsiella pneumoniae in Spain. J Med Microbiol 2012; 61: 864-867.

Poirel L, Yilmaz M, Istanbullu A, Arslan F, Mert A, Bernabeu S, Nordmann P. Spread of NDM-1-producing Enterobacteriaceae in a neonatal intensive care unit in Istanbul, Turkey. Antimicrob Agents Chemother 2014; 58: $2929-2933$.

Sidjabat H, Nimmo GR, Walsh TR, Binotto E, Htin A, Hayashi Y, Li J, Nation RL, George N, Paterson DL. Carbapenem resistance in Klebsiella pneumoniae due to the New Delhi Metallo-beta-lactamase. Clin Infect Dis 2011; 52: $481-484$.

Wilson ME and Chen LH. NDM-1 and the Role of Travel in Its Dissemination. Curr Infect Dis Rep 2012; 14: 213-226.

Yong D, Toleman MA, Giske CG, Cho HS, Sundman K, Lee K, Walsh TR. Characterization of a new metallo-beta-lactamase gene, bla(NDM-1), and a novel erythromycin esterase gene carried on a unique genetic structure in Klebsiella pneumoniae sequence type 14 from India. Antimicrob Agents Chemother 2009; 53: 5046-5054. 